\title{
Investigation of Distributions of $\mathrm{Mn}^{2+}$ Ions in Fully Dehydrated and Fully $\mathrm{Mn}^{2+}$-exchanged Zeolites $\mathbf{Y},\left|\mathbf{M n}_{37.5}\right|\left[\mathbf{S i}_{117} \mathbf{A l}_{75} \mathbf{O}_{384}\right]-\mathrm{FAU}$
}

\author{
Sung Man Seo, Ghyung Hwa Kim, ${ }^{\dagger}$ and Woo Taik Lim*
}

\begin{abstract}
Department of Applied Chemistry, Andong National University, Andong 760-749, Korea. *E-mail: wtlim@andong.ac.kr ${ }^{\dagger}$ Pohang Accelerator Laboratory, Pohang University of Science and Technology, P.O. Box 125, Pohang 790-600, Korea Received May 6, 2010, Accepted June 11, 2010
\end{abstract}

Key Words: Zeolite Y, Ion exchange, Structure, Transition metal, Manganese

Zeolites framework contains channels and windows of molecular dimensions that are based on an infinitely extending threedimensional network of $\mathrm{AlO}_{4}$ and $\mathrm{SiO}_{4}$ tetrahedra linked to each other by sharing all of the oxygens. ${ }^{1}$ Due to these features, they are used as ion-exchangers, adsorbents, molecular sieves, and catalysts in industrial processes. For various applications, transition-metal ions are often introduced into ion-exchangeable site of zeolites by conventional ion-exchange methods. ${ }^{2}$ Transition-metal enclosing zeolites have been shown to catalyze a wide range of organic reactions ${ }^{3}$ such as hydrosulfurization of alcohols, ${ }^{4,5}$ oxidation of alkanes, ${ }^{6,7}$ decomposition of nitromethane, ${ }^{8}$ and Fischer-Tropsch catalysis. ${ }^{9}$

To understand the catalytic sites and properties of transitionmetal ion-exchanged zeolites, it is effective to determine the positions and occupancies of those ions within the cavities of zeolite by single-crystal $\mathrm{X}$-ray diffraction technique. ${ }^{2} \mathrm{Mn}^{2+}$ ion having $\mathrm{d}^{5}$ electron arrangement, among the transition metal, have been fully exchanged into zeolite $\mathrm{X},\left|\mathrm{Mn}_{46}\right|\left[\mathrm{Si}_{100} \mathrm{Al}_{92} \mathrm{O}_{384}\right]-$ FAU; $46 \mathrm{Mn}^{2+}$ ions per unit cell were found at sites I and II. ${ }^{10}$ In this study, the distributions of $\mathrm{Mn}^{2+}$ ions in $\mathrm{Mn}^{2+}$-exchanged zeolite Y structure were crystallographically investigated to compare with crystal structure of $\mathrm{Mn}^{2+}$-exchanged zeolite $\mathrm{X}$. ${ }^{11}$ It was also done as a test of the suitability of these zeolite $\mathrm{Y}$ crystals for further work.

X-ray diffraction data for two single crystals were collected at 294(1) K using an ADSC Quantum210 detector at Beamline 4A MXW at The Pohang Light Source. Crystal evaluation and data collection were done using $\lambda=0.76999 \AA$ radiation with a detector-to-crystal distance of $6.0 \mathrm{~cm}$. Preliminary cell constants and an orientation matrix were determined from 36 sets of frames collected at scan intervals of $5^{\circ}$ with an exposure time of 1 second per frame. The basic scale file was prepared using the program HKL2000. ${ }^{12}$ The reflections were successfully indexed by the automated indexing routine of the DENZO pro-

Table 1. Summary of experimental and crystallographic data

\begin{tabular}{lll}
\hline & first crystal & second crystal \\
\hline Crystal cross-section $(\mathrm{mm})$ & 0.28 & 0.30 \\
Ion exchange T $(\mathrm{K})$ & 343 & 343 \\
Ion exchange for $\mathrm{Mn}^{2+}($ day, $\mathrm{mL})$ & 20,200 & 20,200 \\
Dehydration T $(\mathrm{K})$ & 723 & 723 \\
Crystal color & pale brown & pale brown \\
Data collection T $(\mathrm{K})$ & $294(1)$ & $294(1)$ \\
Space group & $F d \overline{3} m$ & $F d \overline{3} m$ \\
X-ray source & Pohang Light Source, Beamline & $4 \mathrm{~A}$ MXW \\
Wavelength $(\AA)$ & 0.76999 & 0.76999 \\
Unit cell constant, $a(\AA)$ & $24.659(1)$ & $24.657(1)$ \\
2 $\theta$ range in data collection $(\mathrm{deg})$ & 60.59 & 60.73 \\
Total reflections harvested & 63,895 & 64,045 \\
No. of unique reflections, $m$ & 893 & 894 \\
No. of reflections with $F_{\mathrm{o}}>4 \sigma\left(F_{\mathrm{o}}\right)$ & 878 & 875 \\
No. of variables, $s$ & 49 & 49 \\
Data/parameter ratio, $m / s$ & 18.2 & 18.2 \\
Weighting parameters, $a / b$ & $0.060 / 161.8$ & $0.061 / 189.3$ \\
Initial error indices & & \\
$R_{1} / w R_{2}\left(F_{\mathrm{o}}>4 \sigma\left(F_{\mathrm{o}}\right)\right)^{a}$ & $0.3857 / 0.8159$ & $0.3817 / 0.8138$ \\
Final error indices & & \\
$R_{1} / w R_{2}\left(F_{\mathrm{o}}>4 \sigma\left(F_{\mathrm{o}}\right)\right)^{a}$ & $0.0508 / 0.1468$ & $0.0510 / 0.1487$ \\
$R_{1} / w R_{2}(\text { all intensities })^{b}$ & $0.0513 / 0.1482$ & $0.0516 / 0.1504$ \\
Goodness-of-fit & 1.270 & 1.245 \\
\hline
\end{tabular}

${ }^{a} R_{1}=\Sigma\left|F_{\mathrm{o}}-\right| F_{\mathrm{c}} \mid / \Sigma F_{\mathrm{o}}$ and $w R_{2}=\left[\Sigma w\left(F_{\mathrm{o}}{ }^{2}-F_{\mathrm{c}}\right)^{2} / \Sigma w\left(F_{\mathrm{o}}{ }^{2}\right)^{2}\right]^{1 / 2} ; R_{1}$ and $w R_{2}$ are calculated using only the 878 and 875 reflections for which $F_{\mathrm{o}}>4 \sigma\left(F_{\mathrm{o}}\right) .{ }^{b} R_{1}$ and $w R_{2}$ are calculated using all 893 and 894 unique reflections measured. ${ }^{c}$ Goodness-of-fit $=\left(\Sigma w\left(F_{\mathrm{o}}{ }^{2}-F_{\mathrm{c}}{ }^{2}\right)^{2} /(m-s)\right)^{1 / 2}$, where $m$ and $s$ are the number of unique reflections and variables, respectively. 
(a)

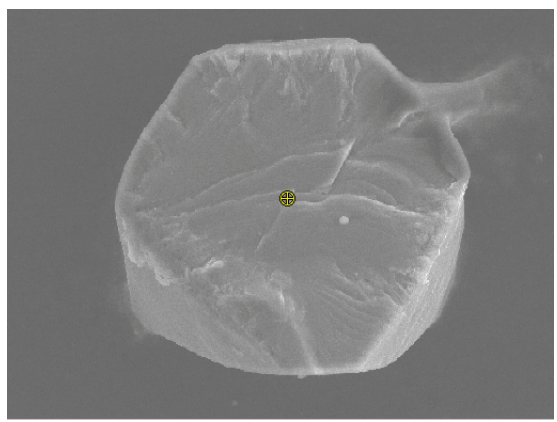

(b)

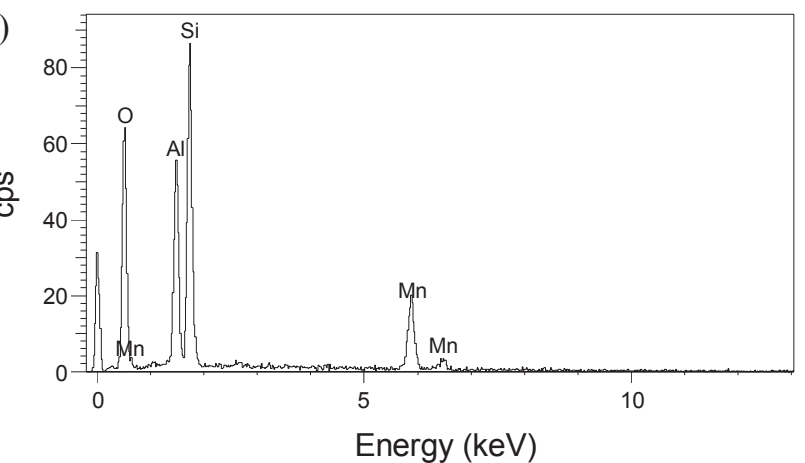

Figure 1. The SEM images of the intentionally broken single crystal (a) and EDX spectra of $\left|\mathrm{Mn}_{37.5}\right|\left[\mathrm{Si}_{117} \mathrm{Al}_{75} \mathrm{O}_{384}\right]$-FAU (b).

Table 2. Compositions ${ }^{a}$ of single crystal by Crystallography (SXRD) ${ }^{b}$ and SEM-EDX ${ }^{c}$

\begin{tabular}{|c|c|c|c|c|c|}
\hline \multirow{2}{*}{\multicolumn{2}{|c|}{$\begin{array}{c}\text { element/ } \\
\text { analysis method }\end{array}$}} & \multicolumn{2}{|c|}{ first crystal } & \multicolumn{2}{|c|}{ second crystal } \\
\hline & & SXRD & SEM-EDX & SXRD & SEM-EDX \\
\hline \multirow{2}{*}{$\mathrm{Si}$} & No. ${ }^{d}$ & 117.0 & & 117.0 & \\
\hline & At $\%$ & 50.9 & 51.1 & 50.9 & 50.2 \\
\hline \multirow{2}{*}{$\mathrm{Al}$} & No. ${ }^{d}$ & 75.0 & & 75.0 & \\
\hline & At $\%$ & 32.6 & 33.1 & 32.6 & 32.1 \\
\hline \multirow{2}{*}{$\mathrm{Mn}$} & No. ${ }^{d}$ & 38.0 & & 37.8 & \\
\hline & At $\%^{e}$ & 16.5 & 15.8 & 16.5 & 17.7 \\
\hline
\end{tabular}

${ }^{a}$ Compositions calculated without oxygen atoms. ${ }^{b}$ Composition determined by least-square refinement of single-crystal X-ray diffraction data. ${ }^{c}$ Composition determined by energy dispersive $\mathrm{X}$-ray spectroscopy using scanning electron microscope. ${ }^{d}$ Number of atoms per unit cell. ${ }^{e}$ Percent of atomic concentration of the element.

gram. ${ }^{12}$ The 63,895 and 64,045 reflections (see Table 1) were harvested for each crystal by collecting 72 sets of frames with $5^{\circ}$ scans and an exposure time of 1 second per frame. These highly redundant data sets were corrected for Lorentz and polarization effects; negligible corrections for crystal decay were also applied. The cubic space group $F d \overline{3} m$ was determined by the program XPREP. ${ }^{13}$ A summary of the experimental and crystallographic data is presented in Table 1.

After X-ray diffraction data collection, the single crystal of $\mathrm{Mn}^{2+}$-exchanged zeolite $\mathrm{Y}$ was removed from its capillary and was deliberately broken to expose fresh surface for SEM-EDX analysis (see Figure 1(a)). As shown in Figure 1(b), it was confirmed that $\mathrm{Na}^{+}$ions within zeolite $\mathrm{Y}$ were completely ion exchanged with $\mathrm{Mn}^{2+}$ ions, using a JSM-6300 scaning electron

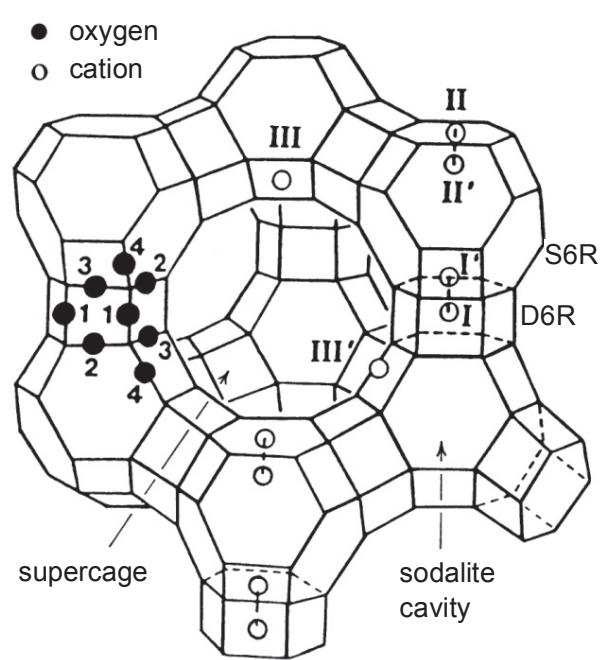

Figure 2. Stylized drawing of the framework structure of zeolite Y. Near the center of the each line segment is an oxygen atom. The nonequivalent oxygen atoms are indicated by the numbers 1 to 4 . There is no evidence in this work of any ordering of the silicon and aluminum atoms among the tetrahedral positions, although it is expected that Loewenstein's rule (ref. 15) would be obeyed. Extraframework cation positions are labeled with Roman numerals.

microscope and an energy dispersive X-ray spectrometer. A comparison of the compositions as determined by crystallographic data and SEM-EDX analysis is presented in Table 2.

Full-matrix least-squares refinement using SHELXL9 $97^{14}$ was done on $F_{\mathrm{o}}{ }^{2}$ using all data for each crystal. Each refinement began with the atomic parameters of the framework atoms $[(\mathrm{Si}, \mathrm{Al})$, $\mathrm{O}(1), \mathrm{O}(2), \mathrm{O}(3)$, and $\mathrm{O}(4)]$ in dehydrated $\left|\mathrm{Tl}_{75}\right|\left[\mathrm{Si}_{117} \mathrm{Al}_{75} \mathrm{O}_{384}\right]-$ FAU. ${ }^{11}$ Each initial refinement used anisotropic thermal parameters and converged to the initial error indices given in Table 1. The final cycles of refinement were done with anisotropic temperature factors for all $\mathrm{Mn}$ atoms and with the final weightingscheme parameters, converged to $R_{1} / w R_{2}=0.0508 / 0.1468$. The four largest peaks on the final difference-Fourier function were not include in the final model either because they were too far from framework oxygen atoms to be cations, or because their peak heights were negligible. The structure was determined again, using a second crystal prepared like the first crystal, to check reproducibility. The final structural parameters and selected interatomic distances and angles are given in Tables 3 and 4 , respectively.

The framework structure of faujasite is characterized by the double 6-ring (D6R, hexagonal prism), sodalite cavity (a cubooctahedron), and supercage (see Figure 2). Each unit cell has 8 supercages, 8 sodalite cavities, 16 D6Rs, 16 12-rings, and 32 S6Rs (single 6-rings). The exchangeable cations, which balance the negative charge of the faujasite framework, usually occupy some or all of the sites shown with Roman numerals in Figure 2. The maximum occupancies at the cation sites I, I', II', II, and III in faujasite are 16, 32, 32, 32, and 48, respectively. Site III' in faujasite studied using space $F d \overline{3} m$ has a maximum occupancy of 96 at Wyckoff positions 96 $(g)$ and 96(h) and 192 at 

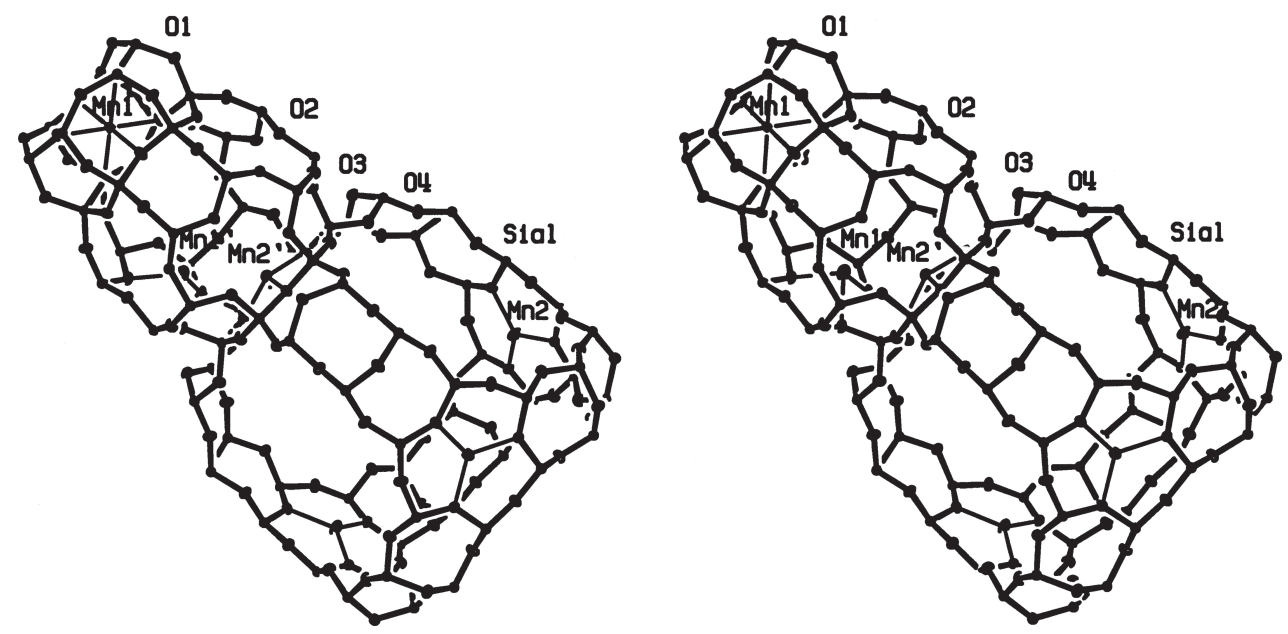

Figure 3. Stereoview of representative a double 6-ring (D6Rs), a sodalite cavity, and a supercage in dehydrated $\left|\mathrm{Mn}_{37.5}\right|\left[\mathrm{Si}_{117} \mathrm{Al}_{75} \mathrm{O}_{384}\right]$-FAU. Of the 16 hexagonal prisms per unit cell, eleven $\mathrm{Mn}^{2+}$ ions are occupied. The zeolite $\mathrm{Y}$ framework is drawn with heavy bonds. The coordination of the exchangeable cations to oxygens of the zeolite framework is indicated by light bonds. Ellipsoids of $25 \%$ probability are shown.

the general Wyckoff positions 192(i). Further description is available. $^{11}$

In the crystal structure of $\left|\mathrm{Mn}_{37.5}\right|\left[\mathrm{Si}_{117} \mathrm{Al}_{75} \mathrm{O}_{384}\right]-\mathrm{FAU}, \mathrm{Mn}^{2+}$ ions were crystallographically found at four distinct sites in contrast to previous result in fully dehydrated structure of $\left|\mathrm{Mn}_{46}\right|$ $\left[\mathrm{Si}_{100} \mathrm{Al}_{92} \mathrm{O}_{384}\right]-\mathrm{FAU}^{11} ; \mathrm{Mn}^{2+}$ ions were found at two equipoints in the structure of $\left|\mathrm{Mn}_{46}\right|\left[\mathrm{Si}_{100} \mathrm{Al}_{92} \mathrm{O}_{384}\right]$-FAU. It is due to the preference of $\mathrm{Mn}^{2+}$ ions by the different local $\mathrm{Si} / \mathrm{Al}$ ordering among the $\mathrm{T}$ atoms in zeolites $\mathrm{X}$ and $\mathrm{Y}$. They have considerably different existence of aluminum contents in the frameworks of zeolites $\mathrm{X}$ and Y. Eleven $\mathrm{Mn}^{2+}$ ions at $\mathrm{Mn}(\mathrm{I})$ are occupied at the center of double 6-ring, site I (see Figure 3 and Table 3).
Each $\mathrm{Mn}^{2+}$ ion located at site I are coordinates to six $\mathrm{O}(3)$ oxygens at 2.339(3) $\AA$. The 6.5 and $3 \mathrm{Mn}^{2+}$ ions at $\mathrm{Mn}\left(\mathrm{I}^{\prime}\right)$ and $\mathrm{Mn}(\mathrm{II}$ ') are recessed $c a .1 .32$ and $0.64 \AA$ into the sodalite cavity from its three $\mathrm{O}(3)$ and $\mathrm{O}(2)$ oxygen plane where it coordinates at $2.300(7)$ and 2.219(5) $\AA$ to those three oxygens for sites I' and II, respectively. These are longer than the sum of corresponding conventional ionic radii of $\mathrm{Mn}^{2+}$ and $\mathrm{O}^{2-}, 0.80+1.32=2.12 \AA^{16}$ (see Figure 3 and Table 4). The angles of $\mathrm{O}(3)-\mathrm{Mn}\left(\mathrm{I}^{\prime}\right)-\mathrm{O}(3)$ and $\left.\mathrm{O}(2)-\mathrm{Mn}(\mathrm{II})^{\prime}\right)-\mathrm{O}(2)$ are $90.4(3)$ and $112.0(3)^{\circ}$, respectively.

The remaining $17 \mathrm{Mn}^{2+}$ ions occupied at site II in the supercage, adjacent to an unshared hexagonal face of a sodalite cage, bond to three $\mathrm{O}(2) \mathrm{s}$ at 2.132(3) $\AA$, are almost same with the

Table 3. Positional, thermal, and occupancy parameters ${ }^{a}$

\begin{tabular}{|c|c|c|c|c|c|c|c|c|c|c|c|c|c|c|}
\hline \multirow{2}{*}{ atom } & \multirow{2}{*}{$\begin{array}{l}\text { Wyckoff } \\
\text { position }\end{array}$} & \multirow{2}{*}{$\begin{array}{l}\text { Cation } \\
\text { site }\end{array}$} & \multirow{2}{*}{$\mathrm{x}$} & \multirow[b]{2}{*}{$\mathrm{y}$} & \multirow{2}{*}{$\mathrm{z}$} & \multirow{2}{*}{${ }^{b} U_{11}$} & \multirow{2}{*}{$U_{22}$} & \multirow{2}{*}{$U_{33}$} & \multirow{2}{*}{$U_{23}$} & \multirow{2}{*}{$U_{13}$} & \multirow{2}{*}{$U_{12}$} & \multicolumn{3}{|c|}{${ }^{c}$ Occupancy } \\
\hline & & & & & & & & & & & & initial & varied & fixed \\
\hline \multicolumn{15}{|c|}{ first crystal } \\
\hline $\mathrm{Si}, \mathrm{Al}$ & $192(i)$ & & $-533(1)$ & $1226(1)$ & $359(1)$ & $176(5)$ & $125(4)$ & $139(4)$ & $-22(2)$ & $-4(3)$ & $-11(2)$ & 192 & & \\
\hline $\mathrm{O}(1)$ & $96(h)$ & & $-1070(1)$ & 0 & 1070(1) & $314(11)$ & $312(17)$ & $314(11)$ & $-96(9)$ & $-24(14)$ & $-96(9)$ & 96 & & \\
\hline $\mathrm{O}(2)$ & $96(g)$ & & $-19(1)$ & $-19(1)$ & 1464(1) & $254(10)$ & $254(10)$ & $202(15)$ & $10(8)$ & $10(8)$ & $76(12)$ & 96 & & \\
\hline $\mathrm{O}(3)$ & $96(g)$ & & $-310(1)$ & $634(1)$ & $634(1)$ & $316(17)$ & $297(11)$ & $297(11)$ & 103(13) & $78(10)$ & $78(10)$ & 96 & & \\
\hline $\mathrm{O}(4)$ & $96(g)$ & & $813(1)$ & $813(1)$ & $3155(2)$ & 261(11) & 261(11) & $451(21)$ & $3(10)$ & $3(10)$ & 104(13) & 96 & & \\
\hline $\mathrm{Mn}(\mathrm{I})$ & $16(c)$ & I & 0 & 0 & 0 & $180(7)$ & $180(7)$ & $180(7)$ & $34(5)$ & $34(5)$ & $34(5)$ & & $11.2(1)$ & 11.0 \\
\hline $\mathrm{Mn}(\mathrm{I} ')$ & $32(e)$ & I' & $623(2)$ & $623(2)$ & $623(2)$ & $513(29)$ & $513(29)$ & $513(29)$ & $146(25)$ & $146(25)$ & $146(25)$ & & $6.6(2)$ & 6.5 \\
\hline Mn(II') & $32(e)$ & II' & 2016(3) & 2016(3) & 2016(3) & $82(37)$ & $82(37)$ & $82(37)$ & $-50(24)$ & $-50(24)$ & $-50(24)$ & & $3.1(3)$ & 3.0 \\
\hline \multirow[t]{2}{*}{$\mathrm{Mn}(\mathrm{II})$} & $32(e)$ & II & $2209(2)$ & $2209(2)$ & $2209(2)$ & $454(18)$ & $454(18)$ & $454(18)$ & $229(18)$ & $229(18)$ & $229(18)$ & & 17.1(3) & 17.0 \\
\hline & & & & & & & & & & & & $\Sigma \mathrm{Mn}^{2+}$ & $=38.0(2)$ & 37.5 \\
\hline \multicolumn{15}{|c|}{ second crystal } \\
\hline $\mathrm{Mn}(\mathrm{I})$ & $16(c)$ & I & 0 & 0 & 0 & $176(7)$ & $176(7)$ & $176(7)$ & $36(5)$ & $36(5)$ & $36(5)$ & & $11.4(1)$ & 11.0 \\
\hline $\mathrm{Mn}\left(\mathrm{I}^{\prime}\right)$ & $32(e)$ & I' & $620(2)$ & $620(2)$ & $620(2)$ & $481(29)$ & $481(29)$ & 481(29) & $118(25)$ & $118(25)$ & $118(25)$ & & $6.5(2)$ & 6.5 \\
\hline Mn(II') & $32(e)$ & II' & 2014(3) & 2014(3) & 2014(3) & $68(39)$ & $68(39)$ & 68(39) & $-55(25)$ & $-55(25)$ & $-55(25)$ & & $2.9(3)$ & 3.0 \\
\hline \multirow[t]{2}{*}{$\mathrm{Mn}(\mathrm{II})$} & $32(e)$ & II & $2212(2)$ & $2212(2)$ & $2212(2)$ & 467(19) & $467(19)$ & $467(19)$ & $250(19)$ & $250(19)$ & $250(19)$ & & $17.0(3)$ & 17.0 \\
\hline & & & & & & & & & & & & \multicolumn{2}{|c|}{$\Sigma \mathrm{Mn}^{2+}=37.8(2)$} & 37.5 \\
\hline
\end{tabular}

${ }^{\bar{a}}$ Positional parameters $\times 10^{4}$ and thermal parameters $\times 10^{4}$ are given. Numbers in parentheses are the estimated standard deviations in the units of the least significant figure given for the corresponding parameter. ${ }^{b}$ The anisotropic temperature factor is exp[-2 $\left.\pi^{2} a^{-2}\left(U_{11} h^{2}+U_{22} k^{2}+U_{33} l^{2}+2 U_{23} k l+2 U_{13} h l+2 U_{12} h k\right)\right]$. ${ }^{c}$ Occupancy factors are given as the number of atoms or ions per unit cell. 
Table 4. Selected interatomic distances $(\AA)$ and angles $(\mathrm{deg})^{a}$

\begin{tabular}{lcc}
\hline & first crystal & second crystal \\
\hline (Si,Al)-O(1) & $1.6383(16)$ & $1.6383(16)$ \\
(Si,Al)-O(2) & $1.6784(13)$ & $1.6775(14)$ \\
(Si,Al)-O(3) & $1.7019(16)$ & $1.7026(16)$ \\
(Si,Al)-O(4) & $1.6240(10)$ & $1.6243(10)$ \\
Mean (Si,Al)-O & $\mathbf{1 . 6 6 0 7 ( 1 6 )}$ & $\mathbf{1 . 6 6 0 7 ( 1 6 )}$ \\
Mn(I)-O(3) & $2.339(3)$ & $2.336(3)$ \\
Mn(I')-O(3) & $2.300(7)$ & $2.295(7)$ \\
Mn(II')-O(2) & $2.219(5)$ & $2.224(5)$ \\
Mn(II)-O(2) & $2.132(3)$ & $2.134(3)$ \\
O(1)-(Si,Al)-O(2) & $113.19(12)$ & $113.17(12)$ \\
O(1)-(Si,Al)-O(3) & $105.94(15)$ & $105.87(16)$ \\
O(1)-(Si,Al)-O(4) & $112.74(17)$ & $112.72(17)$ \\
O(2)-(Si,Al)-O(3) & $106.03(14)$ & $106.07(15)$ \\
O(2)-(Si,Al)-O(4) & $106.18(16)$ & $106.24(16)$ \\
O(3)-(Si,Al)-O(4) & $112.68(17)$ & $112.71(18)$ \\
(Si,Al)-O(1)-(Si,Al) & $132.18(23)$ & $132.28(24)$ \\
(Si,Al)-O(2)-(Si,Al) & $135.74(20)$ & $135.80(20)$ \\
(Si,Al)-O(3)-(Si,Al) & $125.48(19)$ & $125.42(20)$ \\
(Si,Al)-O(4)-(Si,Al) & $158.57(26)$ & $158.59(27)$ \\
O(3)-Mn(I)-O(3) & $89.45(12), 90.56(12)$ & $89.54(13), 90.46(13)$ \\
O(3)-Mn(I)-O(3) & $90.4(3)$ & $91.6(3)$ \\
O(2)-Mn(II')-O(2) & $112.0(3)$ & $111.7(3)$ \\
O(2)-Mn(II)-O(2) & $119.31(6)$ & $119.22(6)$ \\
\hline
\end{tabular}

${ }^{a}$ The numbers in parentheses are the estimated standard deviations in the units of the least significant digit given for the corresponding parameter.

sum of corresponding conventional ionic radii of $\mathrm{Mn}^{2+}$ and $\mathrm{O}^{2-}$, $0.80+1.32=2.12 \AA$, indicating a stronger interaction with the framework $^{16}$ (see Figure 3 and Table 4). The O(2)-Mn(II)-O(2) angle is $119.31(6)^{\circ}$, indicative of near trigonal planar. No cations are found at sites III or III', which are clearly less favorable for $\mathrm{Mn}^{2+}$ ions in dehydrated zeolite $\mathrm{Y}$, it can also be seen in dehydrated $\mathrm{Mn}^{2+}$-exchanged zeolite $\mathrm{X}^{11}$. The structural determination of a second crystal prepared from the same batch as the first one reveals the reproducibility. Further single-crystal structural analyses of organic compound sorption complexes of anhydrous fully $\mathrm{Mn}^{2+}$-exchanged zeolites $\mathrm{Y}$ are now in progress, which will be published in due course.

\section{Experimental Section}

Large single crystals of zeolite $\mathrm{Y}(\mathrm{Si} / \mathrm{Al}=1.56)$ with diameters up to $0.30 \mathrm{~mm}$, stoichiometry $\mathrm{Na}_{75} \mathrm{Si}_{117} \mathrm{Al}_{75} \mathrm{O}_{384}$, were synthesized at Nano Material Structure Research Laboratory in Andong National University. ${ }^{11}$ To prepare $\mathrm{Mn}^{2+}$-exchanged zeolite $\mathrm{Y}(\mathrm{Mn}-\mathrm{Y})$, crystals of hydrated Mn-Y were prepared by static ion-exchange of Na-Y with aqueous $0.1 \mathrm{M} \mathrm{Mn}\left(\mathrm{NO}_{3}\right)_{2}$. $x \mathrm{H}_{2} \mathrm{O}$ (Aldrich, $99.99 \%$ ). This was done by mixing $10 \mathrm{mg}$ of hydrated $\mathrm{Na}-\mathrm{Y}$ with $10 \mathrm{~mL}$ of $0.1 \mathrm{M} \mathrm{Mn}\left(\mathrm{NO}_{3}\right)_{2}$ and then stirred on a shaking incubator for $24 \mathrm{~h}$ at $343 \mathrm{~K}$. This was repeated 20 times with fresh $\mathrm{Mn}\left(\mathrm{NO}_{3}\right)_{2}$ solution. The product was ovendried at $323 \mathrm{~K}$ for 1 day. Two of these, fully dehydrated and fully $\mathrm{Mn}^{2+}$-exchanged zeolite $\mathrm{Y}$ crystals were prepared by under dynamic vacuum to $723 \mathrm{~K}(25 \mathrm{~K} / \mathrm{h})$ and both at $1 \times 10^{-6}$ Torr for 3 days, respectively. The second single crystal was prepared to check reproducibility.

Supporting Information Available. Tables of calculated and observed structure factors (20 pages). The supporting materials are available via the Internet http://www.kcsnet.or.kr/bkcs.

Acknowledgments. We gratefully acknowledge the support of beamline 4A MXW at the Pohang Light Source, Korea, for their diffraction and computing facilities. This work was carried out with the support of "Cooperative Research Program for Agriculture Science \& Technology Development (PJ006851)" Rural Development Administration, Republic of Korea.

\section{References}

1. Breck, D. W. Zeolite Molecular Sieves; Wiley: New York, 1974.

2. Bae, D.; Seff, K. Microporous Mesoporous Mater. 1999, 33, 265.

3. Arends, I. W. C. E.; Sheldon, R. A.; Wallau, M.; Schuchardt, U. Angew. Chem. Int. Ed. Engl. 1997, 36, 1144.

4. Schulz-Ekloff, G.; Wöhrle, D.; Iliev, V.; Ignatzek, E.; Andreev, A. Stud. Surf. Sci. Catal. 1989, 46, 315.

5. Ziółek, M.; Nowińska, K.; Leksowska, K. Zeolites 1992, 12, 710.

6. Vanoppen, D. L.; De Vos, D. E.; Genet, M. J.; Rouxhet, P. G.; Jacobs, P. A. Angew. Chem. Int. Ed. Engl. 1995, 34, 560.

7. Kraushaar-Czarnetzki, B.; Hoogervorst, W. G. M.; Stork, W. H. J. Stud. Surf. Sci. Catal. 1994, 84, 1869.

8. Blower, C. J.; Smith, T. D. Zeolites 1993, 13, 394.

9. Chen, Y. W.; Wang, W. J. Stud. Surf. Sci. Catal. 1993, 75, 1719.

10. Jang, S. B.; Jeonh, M. S.; Kim, Y.; Seff, K. J. Phys. Chem. B 1997, 101,9041 .

11. Lim, W. T.; Seo, S. M.; Wang, L.; Lu, G. Q.; Heo, N. H.; Seff, K. Microporous Mesoporous Mater. 2010, 129, 11.

12. Otwinowski, Z.; Minor, W. Methods Enzymol. 1997, 276, 307.

13. Bruker-AXS (ver. 6.12), XPREP, Program for the Automatic Space Group Determination, Bruker AXS Inc., Madison, Wisconsin, USA, 2001

14. Sheldrick, G. M. SHELXL97, Program for the Refinement of Crystal Structures, University of Gottingen, Germany, 1997.

15. Loewenstein, W. Am. Mineral. 1954, 39, 92.

16. Handbook of Chemistry and Physics, 70th ed.; The Chemical Rubber Co.: Cleveland, OH, 1989/1990; p F-187. 